\title{
Localisation of Hydrogen Fuel Generation from Urine
}

\author{
Priyam Chakravarty \\ B.Tech, Automobile Engineering \\ SRM Institute of Science and \\ Technology \\ Kattankulathur, Tamil Nadu, India
}

\author{
Yash Kesarwani \\ B.Tech, Automobile Engineering \\ SRM Institute of Science and \\ Technology \\ Kattankulathur, Tamil Nadu, India
}

\author{
Karan Kumar Shaw \\ B.Tech, Aerospace Engineering \\ SRM Institute of Science and \\ Technology \\ Kattankulathur, Tamil Nadu, India
}

\begin{abstract}
This paper discusses the possibility of extraction of Hydrogen from urine and using it as a fuel to power various machinery and automobiles which could run on hydrogen fuel. The paper also attempts to show a practical layout of various processes and stages which could facilitate the conversion of urea into hydrogen molecules which can be then stored in compressed chambers and subsequently distributed as required. The design is compact, user-friendly, sustainable and is mostly based on domestic use.
\end{abstract}

Keywords:- Hydrogen, Urine, Urea, Fuel, Machines, Automobiles, User-friendly, Compact, Sustainable.

\section{INTRODUCTION}

The prosperity of modern civilization is fundamentally linked to our capability to harness energy, primarily from the fossil fuels like oil, coal, and natural gas. Today with ever growing population and scarce fossil sources, the degree to which we use energy has never ending consequences. We must look for sustainable and local energy harnessing methods to avoid the negative impacts on global climatic change, the growing risk of supply disturbance, price uncertainty and air pollution that are associated with today's energy sources. Renewable, clean energy provides dependable power supplies and fuel multifariousness, which enhances energy security and with lower risk of fuel spills, and reduce the need for imported fuels. Renewable energy also helps conserve the nation's natural resources. Electricity production is number one source of greenhouse gases. Emissions from coal power plants include harmful gases and matter, and are responsible for respiratory illness and premature death like children and the elderly. Also, these particulate matter and emissions are transported causing serious pollution and adds on to the carbon footprint.

We should look into designing compact, efficient and clean ways to harness energy in a more local way; for example, for every household to harness and effectively use the energy produced from urine (urea as the raw material), which is in fact a renewable and clean source.

Although Hydrogen is the superabundant element in the universe, on Earth it is locked away in form of molecules such as water $\left(\mathrm{H}_{2} \mathrm{O}\right)$. The Electrolysis of $\mathrm{H}_{2} \mathrm{O}$ is in fact very expensive as it requires very high energy to break the strong Hydrogen-Oxygen bonds. And it also makes less sense to expend so much energy to harness lesser or equivalent amount of energy. Whereas urine consists of urea, $\left(\mathrm{NH}_{2}\right)_{2} \mathrm{CO}$. Nitrogen-Hydrogen bonds in urea are much weaker than Hydrogen-Oxygen bonds in water. So, it is much easier to separate Hydrogen atoms from urea and during the electrochemical process, pure hydrogen is produced at the cathode. We shall discuss about the processes below.

\section{WHY URINE?}

Currently, Stream reforming is the primary source of the hydrogen which is nothing just another fossil fuel. The idea of the hydrogen-based economy was to obtained it from electrolysis from cheap clean electricity, but it just was found to be inefficient. Also, transportation, handling and storage adds on to the carbon footprint. Research in the last decade have shown that we can get twice as much hydrogen from urea present in urine with less energy investment as compared to water.

Hydrogen powered car has become a popular transportation fuel with its exhaust product as only water. The main advantage of urine over water for this kind of processes, is its weak hydrogen bonds which can be easily broke with little supply of energy whereas in water hydrogen has stronger bonds and requires greater energy to produce hydrogen.

\section{DESIGN COMPONENTS}

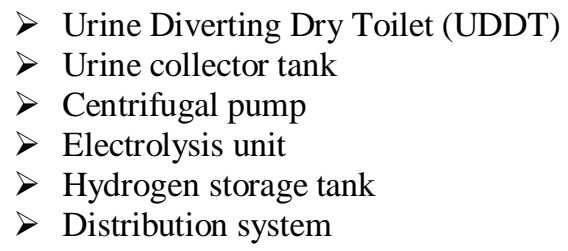

\section{PROCESS}

Preliminary steps include separation of urine from faeces and water by UDDT and collecting an almost $60 \%$ dry form of urea in a collection tank. A pump might be used to push the urea from the urine collection tank to the electrolysis bed. A nickel-based electrode can be used to persnickety and efficiently oxidize the urea.

The Hydrogen is later transported, collected and stored at appreciable pressure and low temperature. 
ISSN No:-2456-2165

\section{MAJOR COMPONENTS}

\section{A. Urine Diverting Dry Toilet (UDDT)}

A urine-diverting dry toilet (UDDT) is a kind of dry toilet with urine deviation that is used to provide protected and cheap sanitation. The separate accumulation of faeces and urine without any flush water serve several benefits, such as smell-free operation as well as bacteria reduction by drying. The dried excreta from this operation can be used regularly in agriculture. The most striking features of the UDDT are: source diversification of urine and faeces; less wastage of water; and ventilated chambers for excreta storage and treatment.

This separation of urine from faeces is obtained by designing toilet bowl which works on Coanda Effect. In order to make this design effective, it is suggested that user must direct their urine flow against the internal walls of the toilet bowl so that it is collected in a small container that is transferred onto the base of the toilet bowl.

UDDTs can be of different types: bench type, squat type, single vault, double vault, portable etc.

We have chosen a UDDT in this design as it will efficiently separate the urine from faeces and can be collected separately in an underground container where after it can be easily used in the electrolysis unit. This separation also helps to collect dry faeces in another container. After it is totally dried up with moisture content less than $20 \%$, it can be reused in agricultural activities. Also taking into account it's waterless operation through Coanda effect or centrifugal effect, it can be very helpful in water-scarce regions and hence is a sustainable sanitation methodology.

UDDT contains some of the following important elements:

It has urine deviating toilet seat or squatting pan.

$>$ It has a provision to remove the anal cleansing water in different direction to collect and disposed off properly.

$>$ It has two chambers usually above ground for excreta collection \& drying as well as to protect it from rain

$>$ It also has sophisticated pee piping system connecting from the user interface to an infiltration system.

$>$ It also has ventilation pipe to squander moisture and odors from the chamber.

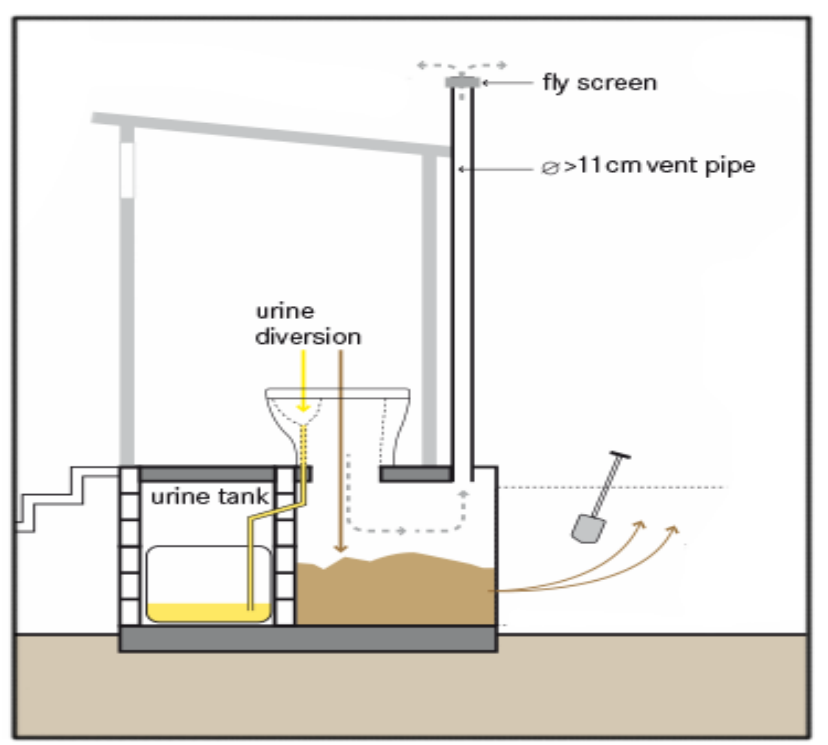

Fig 1:- Schematic diagram of UDDT operation

Advantages:

- It doesn't require a continuous water supply.

- It is an odorless operation.

- It can be easily repaired with basic tools

- It requires low investment and operational costs.

- Suitable for all types of users

$>$ Disadvantages:

- It needs training and acceptance to be used correctly.

- It is prone to misuse and chocking with faeces.

Few designs which greatly impacts this project are:

- Faeces should not do not fall into and block the urine transmission pipe.

- There are also 3-hole separating toilets that allow anal cleansing water into the tank different from urine and excreta collection tank

- The urine has the tendency to rust metals; therefore, metallic pipers should be avoided.

The UDDT is basically made up of materials like concrete and wire mesh or plastic.
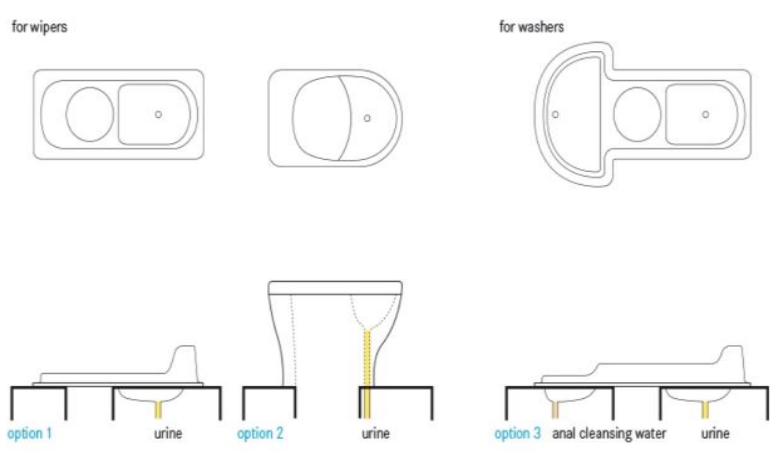

Fig 2:- Different designs of UDDT 


\section{B. Urine Electrolysis (Urinolysis)}

As of now, we have seen how the human waste is separated, collected, dried, transported. This section mainly focuses on the chemical treatment with urine in order to obtained hydrogen. The process discussed here lab-based treatment in small amount of urea which can be implemented on industrial level depending upon the available necessary equipment \& chemicals. One molecule of Urea consists of elements like $\mathrm{H}, \mathrm{C}, \mathrm{O}$ and $\mathrm{N}$. Here we intend to demonstrate a simple technique for improving hydrogen resources for energy usability by recycling waste materials such as urine and human excreta. Fig. 2 represents the basic arrangement to carry out chemical reaction.

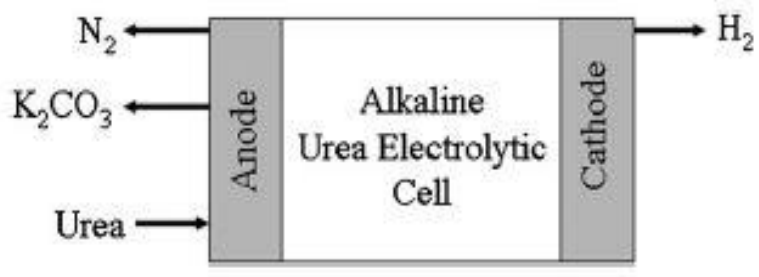

Fig 3:- Diagram showing direct urea-to-hydrogen conversion

\section{Working:}

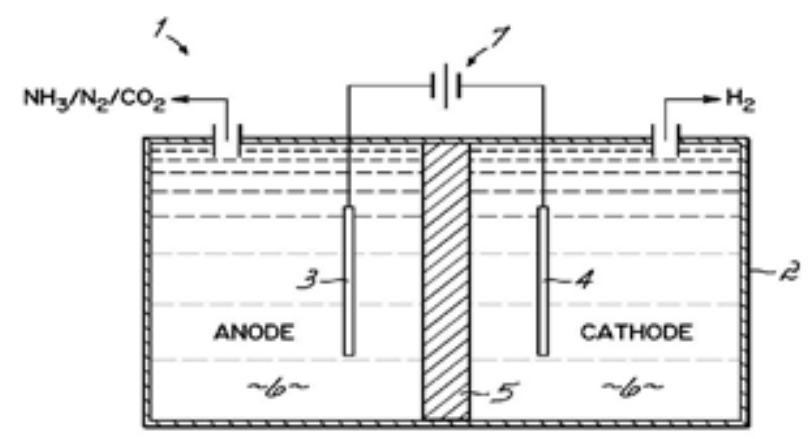

Fig 4:- Basic Setup for electrolysis

From the figure 4, 1 representing a simple electrolytic cell that consists of a tank $\mathbf{2}$, made of light gauge iron composition. It contains two electrodes cathode $\mathbf{4}$ and anode $\mathbf{3}$ which is placed on the opposite sides of separator $\mathbf{5}$ inside electrolytic solution 6 . The electrolyte solution is nothing but majorly consists of urea. The anode $\mathbf{3}$ and cathode $\mathbf{4}$ are directly attached to a voltage source $\mathbf{7}$, which provides the electrical energy for the electrolysis of urea. The anode and cathode comprise a conductor which is coated with more active conducting component like cobalt, copper, iridium, iron, nickel, platinum.

\section{Experiment:}

On performing the experiment with setup as described above, we observed that $0.33 \mathrm{M}$ urea in electrolyte undergoes electrochemical reaction where it is oxidized in presence of nickel, in order as shown in equation (1-4).

$$
\begin{aligned}
& \mathrm{CO}\left(\mathrm{NH}_{2}\right)_{2(\mathrm{aq})}+6 \mathrm{OH}^{-} \rightarrow \mathrm{N}_{2(\mathrm{~g})}+5 \mathrm{H}_{2} \mathrm{O}_{(\mathrm{l})}+\mathrm{CO}_{2(\mathrm{~g})}+6 \mathrm{e}^{-} \ldots \\
& \mathrm{Ni}(\mathrm{OH})_{2(\mathrm{~s})}+\mathrm{OH}^{-} \rightarrow \mathrm{NiOOH}_{(\mathrm{s})}+\mathrm{H}_{2} \mathrm{O}_{(\mathrm{l})}+\mathrm{e}^{-} \ldots \ldots \ldots \ldots \ldots \ldots \ldots \ldots \ldots \ldots \ldots \ldots \ldots \ldots \ldots \ldots \ldots \ldots \ldots \ldots \\
& 6 \mathrm{H}_{2} \mathrm{O}_{(\mathrm{l})}+6 \mathrm{e}^{-} \rightarrow 3 \mathrm{H}_{2(\mathrm{~g})}+6 \mathrm{OH}^{-} \ldots \ldots \ldots \ldots \ldots \ldots \ldots \ldots \ldots \ldots \ldots \ldots \\
& \mathrm{CO}\left(\mathrm{NH}_{2}\right)_{2(\mathrm{aq})}+\mathrm{H}_{2} \mathrm{O}_{(\mathrm{l})} \rightarrow \mathrm{N}_{2(\mathrm{~g})}+3 \mathrm{H}_{2(\mathrm{~g})}+\mathrm{CO}_{2(\mathrm{~g})} \ldots \ldots \ldots \ldots \ldots
\end{aligned}
$$

Urea gets oxidized at the anode (equation (1)) on the supply of current at electrode potential of $-0.46 \mathrm{~V}$. This is followed by alkaline reduction of water as evident in (equation (3)) occurs on the cathode supplied potential of $0.83 \mathrm{~V}$. Overall, we get hydrogen after equation (4). We also found out that an electrolytic cell at potential of only $0.37 \mathrm{~V}$ is required to electrolyze urea at standard conditions. This is remarkably less than the $1.23 \mathrm{~V}$ required to electrolyze water thereby generating $70 \%$ cheaper hydrogen [2].

\section{Storage and Distribution}

With an ongoing evolution to renewable, alternating source such as solar and wind power energy, it has become clear that we need new methods to store the electric energy to complete the demand. In quest of finding the solution to this problem we thought about hydrogen-based energy.

Hydrogen is the lightest gas on the earth. One liter of this gas weighs around 90mgs under atmospheric pressure, which means it is 11 times lighter than the air we breathe. It is very challenging to store Hydrogen as it is lightest molecule having a very low density. To drive $100 \mathrm{kms}$ we require approximately $1 \mathrm{~kg}$ of hydrogen which has volume of around $11 \mathrm{~m}^{3}$. Thus, to store Hydrogen economically its storage density must be increased.

Generally, the main goal of the storage of Hydrogen is to reduce the cost of delivered Hydrogen through supply and demand, and to use it for the backup purpose. The challenge of automotive application is to identify the storage methods that can fulfill the requirement under various conditions within the appropriate temperature to smooth heat integration with onboard fuel cell. We have to find a solution which is cost effective, low leakage system, fast withdrawal and injection rate, and very low contamination.

The main technology used to store the Hydrogen are: -

$>$ Physical $\left[\mathrm{H}_{2}(\mathrm{~g})\right.$ and $\left.\mathrm{H}_{2}(\mathrm{l})\right]$

$>$ Adsorption and absorption

> Chemical (Metal Hydrides and Chemical Hydrides).

> Physical based When Hydrogen is stored without any physical and chemical bonding.

Hydrogen Gas The easiest way to decrease the volume of gas at constant temperature is to increase its pressure. At 700 bars, Hydrogen has density of $42 \mathrm{~kg} / \mathrm{m}^{3}$, compared to $0.09 \mathrm{~kg} / \mathrm{m}^{3}$ at normal pressure and temperature. At this pressure, we can store $5 \mathrm{~kg}$ of Hydrogen in 125-liter tank. 
Two main component of hydrogen gas is the storage tank and the compressor unit. Here we are only going to discuss about the storage unit. Due to the operating cost a large amount of hydrogen gas is not stored more than 100 bars above the ground and 200 bars underground. As the storage pressure is limited the hydrogen storage density at 100 bars and $20{ }^{\circ} \mathrm{C}$ the density of Hydrogen is $7.8 \mathrm{~kg} / \mathrm{m}^{3}$. The low density led to large storage specific volume increasing the investment cost. However, a lower storage pressure led to less compression work and lower cost.

The investment cost for the aboveground are higher than that for underground. Thus, underground storage is preferred. As large amount of Hydrogen is already being stored underground at Salt Cavity storage in Teeside, UK and Texas, USA. But these are used because of their resource full locations.] The solution is to store gas in a metal container. As it increases the initial investment cost but it ensures the stability and purity of the hydrogen gas. There is little advantage in burying the vessel in the ground as it saves space, protect against any physical and environmental effect but it all depends on the material and construction of the vessel. But this makes difficult for inspection and to protect from corrosion (this problem can be solved by painting the outer surface of the vessel).

Three main metallic containers to store Hydrogen gas are: -

- Gas Holders, it stores pressure slightly above the atmospheric pressure.

- Spherical Pressure vessels, it stores with maximum pressure up to 20 bars.

- Pipe storage, it stores with maximum pressure of approximately 100 bars.

It is most promising as it stores at high pressure. Around 12 tons of hydrogen gas can be stored in per $\mathrm{km}$ pipeline. In Lined rock carven Skallen, Sweden $35 \mathrm{~m}$ diameter and $5 \mathrm{~m}$ height at 200 bars can store approximately 740 tons of Hydrogen gas.

The construction cost of metal container is due to a phenomenon known as Hydrogen embrittlement, which negatively affects the mechanical properties of the vessel material over time. Today, most car manufactures have opted for this because this technology can store enough hydrogen to enable car that runs on fuel cell to cover between 500 to $600 \mathrm{kms}$. Compressed hydrogen in tanks at 350 bar and 700 bars is used for hydrogen tank systems in vehicles, based on type IV carbon-composite technology.

Liquid Hydrogen To store maximum volume of hydrogen in a restricted volume is to convert hydrogen gas into liquid hydrogen by cooling it down to very low temperature (in case of hydrogen gas to convert into liquid is to cool it down at $-253{ }^{\circ} \mathrm{C}$ ). At $-253{ }^{\circ} \mathrm{C}$ and atmospheric pressure, liquid hydrogen has density of $71 \mathrm{~kg} / \mathrm{m}^{3}$ at this we can store $5 \mathrm{~kg}$ of hydrogen in 75-litre tank. In adding to compression, density may also be increased via condensation. The plus point of liquid hydrogen storage is that, very high hydrogen storage density can be achieved at atmospheric pressure.

Primary concern for storage is energy intensive liquefaction process. Due to its very low boiling point, hydrogen doesn't cool down during throttling process for temperature above $-73{ }^{\circ} \mathrm{C}$. Thus, problem then necessitates precooling liquefaction process by evaporating liquid Nitrogen. After the hydrogen liquefaction, it is important that it should be stored so that evaporation is minimized. Basically, liquid hydrogen storage vessels are doubled walled with high vacuum is applied between the walls. The vacuum between the walls minimizes the heat transfer via convection and conduction. The space between the walls also contain some additional material such as (alumina coated polyester sheets and alternating layer of aluminum foils and glass fiber etc.) to protect against heat transfer via radiation. Liquid hydrogen has extremely low boiling point due to which it can cause frostbite and hypothermia. Some accidental air leakage will cause moisture in the system that causes water to turn into ice and may plug pipelines.

The liquid hydrogen tank material should be selected on its mechanical property at low temperature. Some material changes from ductile to brittle as temperature goes down, and this can start before reaching to the cryogenic temperature. Materials having low temperature embrittlement should not be used as the storage tank material. As many carbon steel materials are brittle below ambient temperature, precaution should be taken before enter of chilled hydrogen. In most of applications, liquid hydrogen is vaporized and warmed prior to use.

Cryo-compressed cold hydrogen are slightly different from the liquid hydrogen, the main difference is that when hydrogen gets warm due to heat transfer with the environment, the tank is allowed to go to pressure higher than liquid storage. Due to which it takes more time before hydrogen has to vent and in driving situation car uses enough hydrogen to keep pressure well below the venting limit. A study has shown that it cost $\$ 0.12$ mile (cost of fuel and very other associated cost included) for cryocompressed hydrogen, while it cost gas vehicle around $\$ 0.05$ to $\$ 0.07$ per mile.

This type of technology is generally used in Space programs (Air Liquide tank contain 28 tons of liquid hydrogen having weight only 5.5 tons and their casing is not more than $1.3 \mathrm{~mm}$ thick).

> Adsorption and absorption based when hydrogen is absorbed into material held by weak Van Der Waal Bonds.

Due to weakness of the Van Der Waal forces, low temperature and elevated pressure must typically be applied to achieve significant hydrogen storage densities using adsorption most commonly by using Liquid Nitrogen. Most significant challenge of adsorption-based hydrogen will be heat management as due to weak forces the adsorption reaction is exothermic reaction. And we have to ensure that 
the heat is removed from the system to reach adequate amount of adsorption. And heat transfer with environment causes temperature rise. These factors cause more cooling requirement which increases the energy consumption and the cost. Therefore, these are not expected for large or small storage. Porous carbon-based materials (Activated carbons are highly porous amorphous carbon materials with high apparent surface area and they can be made from waste materials, such as cigarette butts), graphene, metal-organic frameworks (MOFs) (these have high no. of pores and large surface area which allow higher hydrogen adsorption), porous polymeric materials and zeolites are some common materials used in this technology.

Chemical Based when hydrogen is chemically bonded with other materials.

Metal Hydrides the Hydrogen is bonded with metal hydrides. These bonds are much stronger than that in adsorption. The strong bonding helps to store hydrogen at high density even at ambient temperature but due to that it requires more energy to release chemically bonded hydrogen. Thermolysis (endothermic reaction) and Hydrolysis (exothermic reaction) are two ways to release hydrogen. A vast range of metal hydrides are present for thermolysis but few for hydrolysis reaction. Some metal hydrides are magnesium hydride $\left(\mathrm{MgH}_{2}\right)$, Aluminum hydrides $\left(\mathrm{AlH}_{2}\right)$, intermetallic hydrides, boron hydrides etc.

Chemical Hydrides these are same as metal hydrides in which hydrogen is bonded with chemical hydride. As the chemical hydrides are lighter element than metal hydrides, it shows different properties than that of metal hydrides. Due to the fact most, chemical hydrides are liquid at room temperature, it is easy to store and transport the hydrogen and less heat transfer during the process of hydrogenation and Dehydrogenation. Some chemical hydrides are Ammonia, formic acid, methanol, organic hydrogen carriers (cycloalkanes and N-heterocycles).

Hydrogen can be distributed with these three methods

- Pipelines this is least expensive to deliver large amount of hydrogen but it is very limited.

- Liquified Hydrogen tankers Liquid hydrogen is delivered in this method. It is expensive but it is efficient than high pressure tube trailers for long distance transport through ships and trucks.

If hydrogen is not used at high rate it will boil off (evaporate). The storage and distribution system are very challenging in present times. As it contains less energy per unit volume than all other fuels, transporting, storing and delivering is very expensive than gasoline per gallon. And a new hydrogen pipeline requires large initial investment cost. Most storage technology are still being researched, indicating that sustainable developments are still to be made.
For personal storage in our home we have to find the best solution that is cost effective, safe and high availability of Hydrogen Fuel. The solutions available currently are Underground Storage System and Metal storage Cylinders. Metal cylinder system have more investment cost but it is stable for storage, more purity and it can be stored at any location. In both underground and metal containers the structural integrity and maximum allowable pressure depends upon vessel material. In underground storage system it saves space, protect against natural calamity but there is downside to it as it becomes difficult for inspection and protection against corrosion. So, to conclude the best solution for home use is Metal storage container as it is safe, easy storage compatibility, better distribution system and delivery of hydrogen fuel at any time.

\section{CONCLUSION}

Localizing energy generation from each household or a society/community/neighborhood and collectively distributing to each house by a process where energy required for urea electrolysis is $35 \%$ less and generates $40 \%$ cheaper hydrogen compared to water electrolysis, where the only exhaust by-product is water vapor proves it to be a much efficient and preferred alternative. The source of urine is naturally available from humans and cattle. Also, in this system after hydrogen is produced it will be effectively used to produce constant electricity for homes and as fuel for our future vehicles, so there is much lesser chance of boil-off or hydrogen gas wastage. The best smallscale and cheap solution for storage in our homes or society should be an underground physical based storage system. Also, it can be an effective solution to electricity shortages in villages and remote locations as one litre of urine can produce about six hours of electricity. The dried-up faeces and nitrogen evolved in the anode can be used in agricultural purposes. Thus, we conclude by, in the hope of convincing that the idea can be practically experimented to model out the best design which can aid in the mission of Sustainable Energy Generation.

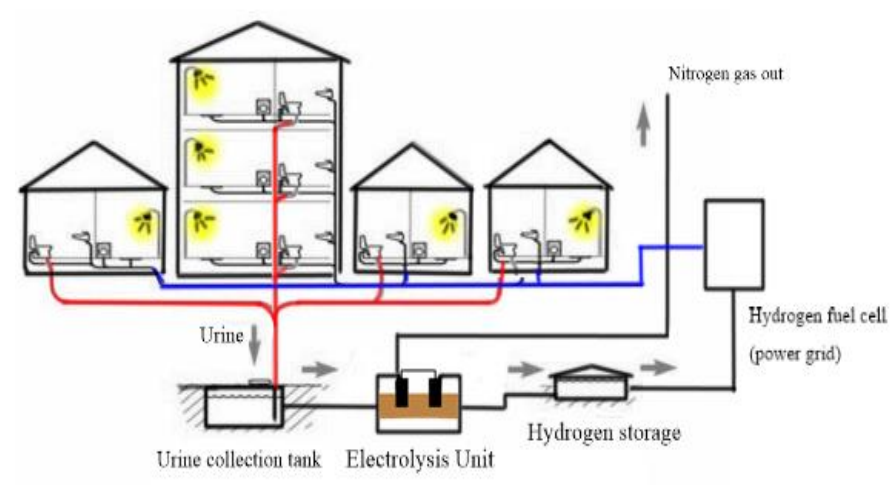

Fig 5:- Layout for small-scale society 


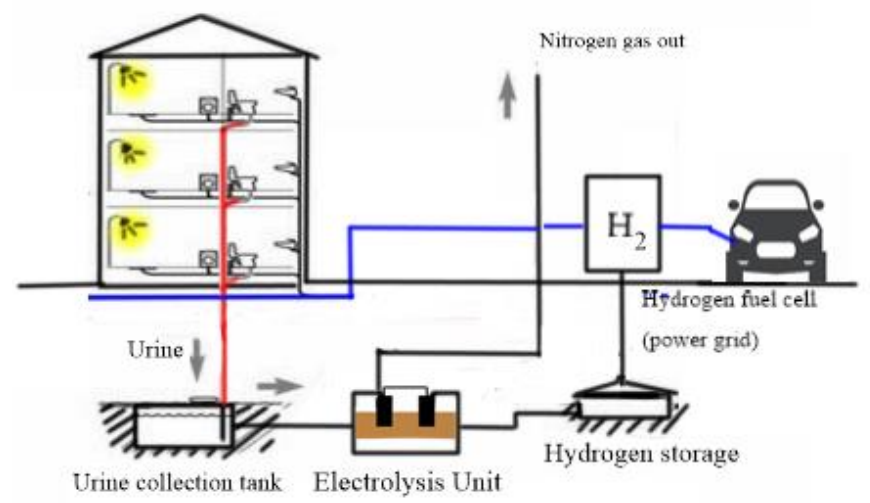

Fig 6:- Layout for small-scale household

In the figures below, the red line indicates urine carrying pipeline and blue line indicates electricity supply lines to the households and Hydrogen fuel cell vehicles.

\section{REFERENCES}

[1]. Research on Applied Bioelectrochemistry,Quaterly Progress Report No. 2, Magna Corporation Contract NaASw-623, 1963.

[2]. H. B. H. Cooper, I. Spencer and W. Herbert, Methods for the production of ammonia from urea and/or biuret, and uses for $\mathrm{NOx}$ and/or participate matter removal, U.S. Pat., 6077 491, 2000.

[3]. D. C. Bouchard, M. K. Williams and R. Y. Surampalli, J. A,. Water Works Association, 1992, 84,85-90.

[4]. D. R. McCubbin, B. J. Apelberg, S. Roe and F. Divita, Environmnetal Science Technology, 2002, 36, 11411146.

[5]. G. G. Bottle, Electrlysis of urea/urine to produce ammonia and hydrogen, electrolysis of urea/urine to ammonia, and methods, uses, and fuel cells related thereto, U.S.Pat.,60/980 056, 2007.

[6]. F. Vitse, m. Cooper and G.G Bottle, J. Power Sources, 2005, 142, 18-26.

[7]. G. G. Botte, F. Vitse and M. Cooper, "Electrocatalysts for the ooxidation of ammoina and their application to hydrogen production, fuel cells,.sensors and purification processes”, U.S. Pat., 2003.

[8]. Havard School of Public Health (2012),"Why we need sustainable energy", http://sitn.hms.harvard.edu/flash/2012/whysustainable/

[9]. Sustainable Sanitation and Water Management Toolbox, 2010, "Urine-Diverting Dry Toilet", https://sswm.info/sswm-solutions-bopmarkets/affordable-wash-services-andproducts/affordable-technologies-sanitation/urinediverting-dry-toilet-\%28uddt $\% 29$

[10]. Joakim Andersson and S. Gronkvist,"large-Scale Storage of Hydrogen",Hydrogen energy Publications LIC, Elsevier 2019.

[11]. Liquid Hydrogen, Wikipedia link: https://en.wikipedia.org/wiki/Liquid_hydrogen

[12]. Compressed Hydrogen, Wikipedia Link: https://en.wikipedia.org/wiki/Compressed_hydrogen
[13]. Hydrogen Storage, wikipedia link: https://en.wikipedia.org/wiki/Hydrogen_storage

[14]. BOC Industrail gases, "Hydrogen storage and Distribution", link: https://www.boconline.co.uk/en/processes/hydrogenenergy/complete-hydrogen-solutions/hydrogendistribution-storage.html

[15]. Air Liquide, "Storing Hydrogen Under Pressure", link: https://energies.airliquide.com/ 